Article

\title{
Do Factory Audits Improve International Labor Standards? An Examination of Voluntary Corporate Labor Regulations in Global Production Networks
}

\author{
Scott R. Sanders *, Michael R. Cope and Elizabeth R. Pulsipher \\ Department of Sociology, Brigham Young University, Provo, UT 84602, USA; michaelrcope@byu.edu (M.R.C.); \\ elizabeth.pulsipher@gmail.com (E.R.P.) \\ * Correspondence: scott_sanders@byu.edu
}

Received: 19 April 2018; Accepted: 23 May 2018; Published: 30 May 2018

\begin{abstract}
This research examined the effects of voluntary factory audits on labor conditions. Sometimes referred to as corporate social responsibility (CSR) codes of conduct, corporations impose voluntary labor standards coupled with regular auditing to help ensure the protection of workers throughout their global production networks (GPNs). While some believe that auditing factories ensures that CSR codes of conduct are followed and helps private corporations promote higher labor standards, others argue that factory audits have little effect on labor standards at the factory level. Using unique panel data of internal factory audit reports of factories in four Southeast Asian countries between 2003 and 2010, this paper sought to understand whether voluntary GPN audits improve labor standards at the factory level. The results showed that a factory's number of audits between 2003 and 2010 did not improve factory working conditions significantly and that the local neighborhood in which a factory is located has a greater effect on changes in factory audit scores. These findings suggest that CSR codes of conduct and auditing alone are not sufficient to improve labor standards in GPNs. Rather, joint private-public collaboration is needed to improve labor conditions for workers in the global south.
\end{abstract}

Keywords: corporate social responsibility; auditing; global production networks; labor

\section{Introduction}

Relatively recent changes in the global economy have contributed to a growing interest in codes of conduct based on principles of corporate social responsibility (CSR). The growth and expansion of global production networks (GPNs) throughout the world has produced a demand for multinational corporations (MNCs), largely those based in the global north, to ensure that minimum labor and environmental standards are used in the production of their goods. At the same time, the increased significance and value of corporate brands have made MNCs with poor working conditions in their GPNs vulnerable to bad publicity. To help protect workers and avoid damage to their public image, many MNCs have adopted voluntary CSR codes of conduct coupled with factory audits in an effort to govern and regulate labor standards within their GPNs. Qualified third parties often perform the audits of GPNs and factories. In theory, MNCs use the information auditors gather to promote higher labor standards, eliminate factories with poor conditions, and protect workers throughout GPNs. In addition, many NGOs and transnational activist groups also use audits to ensure that large corporations are meeting labor standards (Bartley and Child 2014). As a result, factory audits have become a vital tool for multiple parties interested in labor standards. Further, accurate, and perhaps more importantly, reliable information about factory working conditions obtained through audits, has helped create a "credible commitment" for MNCs (Locke et al. 2007). This can lead to greater trust 
between consumers and global brands, which in turn helps reinforce MNCs' motivation to apply CSR codes of conduct throughout their GPNs. It is precisely because audit-generated information plays such a pivotal role in the traditional compliance model that it is essential to know whether continuous long-term auditing actually leads to improved labor conditions. However, the current literature on CSR-based factory audits lacks studies that have examined the long-term effects of auditing on labor conditions (Locke 2013). The research presented below sought to address this limitation for the first time by using panel data of factory audits collected by an independent third party in four Southeast Asian countries between 2003 and 2010. By tracking changes in factory labor audit scores over multiple years, this study examined the effect of continuous factory audits on long-term labor conditions. In addition to examining factory audits' effectiveness in improving working conditions, the way that factory characteristics, as well as local neighborhood environments, affect changes in factory conditions was studied. Our findings showed that although average factory scores demonstrated an improvement overall, after factory characteristics and neighborhood effects were controlled, the number of factory audits did not improve long-term factory labor conditions significantly. However, the results of a logistic regression on the likelihood of a factory being dropped from a GPN after the initial audit suggested that audits can be an effective tool with which to identify and eliminate low performing factories. Therefore, our research indicated that the effectiveness of continuous long-term factory auditing in improving labor conditions is mixed. Audits do not help improve long-term factory conditions, but can be used to filter out factories with the poorest labor standards.

\section{The Promise of CSR Codes of Conduct and Codes of Conduct}

Self-imposed codes of conduct have become a central aspect of many MNCs' CSR policies. These codes are often accompanied by multiple efforts designed to monitor compliance and adoption of labor standards. However, the effectiveness of auditing in changing labor standards has been questioned recently (Bartley 2007; Locke et al. 2009; Vogel 2010; Locke 2013; Bartley and Child 2014). Initially, auditing was used to ensure that adverse practices were eliminated through compliance with national legal and ethical standards within a corporation. Later, the use of auditing evolved in an effort to oversee standards across increasingly complex GPNs (Locke 2013). Over time, auditing efforts became progressively concerned with compliance with GPNs' private, voluntary codes of conduct, especially as they apply to labor, health and safety, and environmental standards. This model of workplace governance has provoked heated debates about the effectiveness of auditing, and whether it leads to greater compliance with CSR codes of conduct and long-term changes in labor conditions.

Critics of voluntary audits argue that they are not designed to improve working conditions, but instead are intended to limit the legal liability of global brands and prevent damage to MNCs' reputations (Bartley 2005). Previous research has found some evidence that auditing contributed to marginal improvements in factory work conditions (Locke 2013). However, despite the widespread adoption of auditing as a way to enforce CSR codes of conduct, there still remains limited empirical evidence that the long-term use of auditing improves labor conditions.

Asymmetric power relations between MNCs and local producers in GPNs are often cited as the major reason auditing can enforce CSR codes of conduct successfully. Essentially, because of their size and economic power, MNCs have the ability to influence local producers' implementation of CSR codes of conduct and standards (Gereffi et al. 2005). This is discussed most often in the global commodity chain literature and stresses that key actors, such as global buyers, must integrate transnational manufacturers in the governance of GPNs (Locke 2013). The implementation of CSR codes of conduct is based on the idea that because MNCs can dictate the location and specification of the end product, they can also choose to make local producers comply with labor and environmental standards as part of their production specifications. Further, GPNs' expansion into new markets and countries means that local producers must compete with a growing number of locations and producers for contracts with MNCs. Thus, more production options increase the power asymmetry between MNCs and local 
producers. Theoretically, GPN audits provide an independent assessment of local producers and help MNCs determine whether local producers are meeting their production specifications.

Although it can be debated whether MNCs have the corporate will to impose CSR codes of conduct on their GPNs, growing pressure from transnational activist networks has led to GPNs' wider adoption of compliance codes (Seidman 2007). Threats to brand value because of boycotts and other campaigns have pressured MNCs to adopt voluntary codes of conduct and resulted in the introduction of independent auditing systems in GPNs. As a result, GPN audits have been adopted widely to help ensure that labor standards are being met throughout GPNs and to protect the brand value of a MNC from any alleged wrongdoing. Therefore, in part, the intent of auditing is to provide evidence that the relative power and influence of MNCs on their GPNs is producing changes in labor standards at the factory level. As a result, it is essential to understand the effects of auditing on factory labor standards. If audits do not improve factory labor standards, then claims MNCs make that their codes of conduct improve labor standards can be seen as a marketing ploy rather than initiatives that improve factory working conditions.

Another key factor in the success of CSR codes of conduct and auditing is applying proper incentives to induce behavioral changes in local producers within GPNs. Sometimes known as deterrence theory in economics, this assumption depicts compliance with CSR codes of conduct as the product of a simple calculation by utility-maximizing actors (Becker 1974). Therefore, local producers weigh the cost of compliance against the probability of being caught violating CSR codes of conduct, as well as the probability of being punished for those violations. In turn, MNCs theoretically reward highly compliant factories with increased or long-term contracts, while those with major violations are penalized by reduced orders and even a termination of the business relationship with the MNC. As a result, auditing plays an essential role for MNCs. Without the insights it provides, it would be impossible for MNCs to know which factories should be rewarded, penalized, or removed from the GPN. Thus, some argue that regular audits provide a clearer understanding of GPNs and the way incentives and penalties are working. Therefore, it has been stated that a long-term collaborative partnership between local producers, MNCs, and third-party auditors can lead to improved working conditions throughout a GPN (Locke 2013).

However, there is a growing body of empirical work that questions the effectiveness of CSR codes of conduct and auditing (Esbenshade 2012). For example, some local producers have become as powerful as MNCs because of their size, prominent position in a GPN, and/or lack of viable alternatives in a GPN. As a result, MNCs have found that some producers in GPNs are now irreplaceable, and therefore, immune to CSR codes of conduct and auditing efforts (Chan et al. 2013). Further, recent research has shown a much more complex and subtle power dynamic between the various parties in GPNs, as well as a decline in MNCs' relative power at various levels of GPNs (Locke et al. 2007). These recent changes in the power dynamics and relationships between MNCs and producers in GPNs call into question whether factory audits have any real effect on factory conditions. However, limited research has examined the effectiveness of audits. One of the few papers that has explored the issue is that of Locke et al. (2007). This paper explored changes in factory conditions in Nike Factories between 1998 and 2005 and found limited improvement associated with auditing. However, this study was limited only to factories in the Nike GPN and relied on cross-sectional factory data. Other papers that have studied auditing have used a case study approach to examine specific countries or a relatively small number of factories (Kolben 2004; Ngai 2005; Locke 2013; Egels-Zandén and Lindholm 2015). However, none of these studies used panel data to track and understand the specific changes that occur in factories for more than three years. This research addressed this limitation in the literature by exploring the effectiveness of CSR codes of conduct and auditing using panel data of factory audits collected by an independent third party between 2003 and 2010. This unique dataset will, for the first time, provide important insights about the effectiveness of audits by examining whether repeated audits are associated with statistically significant improvements in factory conditions. 


\section{Global vs. Local Neighborhoods}

One reason posited for the fact that CSR codes of conduct and auditing do not produce long-term improvements in factory conditions is that they do not change the neighborhood in which the factory is located. MNCs have control over a factory, but cannot change the culture, values, and social norms in the surrounding neighborhood. Neighborhoods are defined by the commonalities and solidarity features shared among the residents of a particular geographic area (Craven and Wellman 1973; Pickvance 1975). A group of people bound together in this way creates the type of community in which they want to live, as well as secures the primary ties within it (Wellman 1979; Mumford 1961, p. 5). In large urban areas, it is evident that neighborhoods are divided along such lines, especially when numerous enclaves or "racial colonies" (Park 1915, p. 582) develop a social organization consistent with race and social class. Wellman (1979) explained this type of phenomenon as a part of the so-called "community saved" argument, in which people will always organize into communities regardless of ecological, demographic, or social circumstances; people seek out and create primary ties by finding others who meet their wants and needs and by incorporating them into their community. Surrounding themselves with people who share their own beliefs and customs helps create a strong community. Thus, neighborhoods tend to develop a homogenous character that generates the same primary ties via similarities in interest, background, and status; these characteristics are asserted to have disappeared in the "community lost" argument (Woodsworth 1911; Park 1915; Wirth 1938; Nisbet 1969; Wellman 1979).

Today, location, city streets, census blocks, and density are not the only factors that define a neighborhood, as they were in the past (Guest and Lee 1984), unless density is combined with significant social characteristics the people within the neighborhoods share (Wirth 1938). Park claimed, " ... [i]n the course of time, every section and quarter of the city takes on something of the character and qualities of the inhabitants. Each separate part of the city is inevitably stained with the peculiar sentiments of the population" (1915, p. 579). As a neighborhood ages, it becomes more and more defined by its own history and residents. A number of effects, particularly social characteristics, tend to be grouped together at the neighborhood level (Sampson et al. 2002). Such effects include socioeconomic status, poverty, wealth, occupational attainment, residential stability, home ownership, tenure, and racial/ethnic composition (Sampson and Bartusch 1998; Sampson 2003; Sampson et al. 2002; Montgomery and Hewett 2005). Neighborhood effects also include crime, adolescent delinquency, social and psychological disorder, low birth weight, infant mortality, injury, school dropout rate, and child maltreatment (Sampson et al. 1997).

Thus, neighborhood effects need to be taken into account when assessing the effectiveness of CSR codes of conduct and audits. Audits may result in a periodic "cleaning" of factories, but those changes may not be present the next year, or even the day after the audit was conducted. In addition, it is possible that improvements in the surrounding neighborhood can have a spillover effect on the factories. Improvements in labor standards in neighboring factories may account for changes in factory conditions, and not simply be the results of continuous auditing. Therefore, to understand whether CSR codes of conduct and auditing affect GPNs, it is essential to examine the neighborhoods in which the factories are embedded as well. To understand the way neighborhoods and the factory's location affect long-term changes in labor standards, this research used geo-referenced data with spatial statistics to help account for neighborhood effects on the changes in factory audit scores.

\section{Data}

A primary challenge in studying factory audits is obtaining data. Most corporations are unwilling to share their audit reports with researchers. In fact, this research is unique because it is one of the only studies that gained access to detailed audit reports, and the only one able to examine the changes in factories over a seven-year period (Locke 2013). Although our data are limited, and only available for the 2003 to 2010 period, their uniqueness allowed this research to provide new and important insights into the relation between factory audits and changes in factory conditions. 
Data for this research were derived from individual factory audit reports conducted by Specialized Technology Resources (STR) between 2003 and 2010. During this seven-year period, STR conducted over 14,000 independent audits annually in factories, warehouses, and distribution centers throughout the world. The audits were contracted to STR by large and small companies seeking to evaluate their GPNs. Each factory audit STR conducted came from an announced on-site, detailed examination of each location. The audits include a review of paperwork and a physical inspection of the work site. STR auditors are trained to make consistent assessments of conditions based on STR standards and metrics, not on local laws or labor practices. The audits examine multiple aspects of the factory's labor management and working conditions, including: hiring practices; the legality of worker permits and papers; the treatment of workers; the safety of the work environment; communication between workers and management; and pay/compensation. Each audit receives a score that ranges from 0 to 100 (see below for a more detailed explanation of the audit score).

This research used audits from factories located in Indonesia, the Philippines, Thailand, and Vietnam. All four of these countries have similar labor standards and are important parts of many GPNs (Miller et al. 2015). In addition, although practices such as child labor are illegal in all four countries, labor standards in many factories do not meet the codes of conduct established by MNCs. Further, MNCs use factory auditing widely in these countries as a way to improve factory conditions (Locke et al. 2007). Finally, data from these four countries were used because of availability. As mentioned above, auditing data are extremely difficult to obtain, and STR was only willing to share data from these four countries between 2003 and 2010.

The panel data consisted of 832 factories audited during the period. Only factories that remained in the GPNs throughout the period were included in the panel data. The panel data allowed this research to examine changes in factory audits scores in specific factories between 2003 and 2010. Data from the four countries were pooled to allow a more robust analysis. The final 832 factories audited between 2003 and 2010 included 21.6\% of the factories located in Indonesia, 18.5\% of those in the Philippines, $28.6 \%$ of those in Thailand, and $31.7 \%$ of those in Vietnam.

In addition to the analysis of the panel data, this research also investigated the number of factories that were dropped from GPNs after the initial STR audit in 2003. Data from all 2003 audits in the four countries were used for this analysis and resulted in a final sample size of 1293.

\section{Methods/Measures}

Our analytical strategy was to describe the mean scores and characteristics of factories in the four countries first. This helped provide context for the regression analysis and illustrate trends in factory conditions overall. In addition, the descriptive statistics showed the relative similarity between Indonesia, the Philippines, Thailand, and Vietnam, which supported the decision to pool their data.

We then generated two multivariate maximum likelihood regressions for the change in the log of factory audit scores between 2003 and 2010. The first model only accounted for the number of audits during the period. This provided a baseline estimate of the effect of auditing on changes in factory conditions and showed whether factories that received more audits reported greater changes in factory conditions. The second spatial regression examined audits' effects on changes in factory conditions by adding variables that controlled for factory characteristics, location, and a spatially lagged variable that helped account for neighborhood effects. This statistical methodological strategy is based on the counterfactual approach to causality established by Weber (1978). That is if the cause occurs so will the effect, and if the effect does not occur, then there is no cause. If our analysis does not show a statistically significant relationship between the number of audits and the change in factory conditions, then there is no effect. Without a statistically significant effect, there is no causal link between auditing and changes in factory conditions. Furthermore, a lack of a statistically significant relationship between the number of audits and the change in factory conditions would question the validity of the main GPN monitoring practices used by MNCs and NGOs. 
We then included a separate analysis using only the 2003 STR audit data to run a logistic regression to predict the likelihood that a factory would be dropped from a GPN to evaluate whether initial audits help filter out factories with poor conditions. Finally, data limitations prohibited the establishment of causality. However, because MNCs are currently using audits under the assumption that continued audits improve labor standards in GPNs (Waddock et al. 2002; Egels-Zandén 2014), simply understanding whether there are significant correlations between the number of factory audits and changes in factory conditions addresses the current lack of evidence of the effectiveness of audits and thus makes a valuable contribution to the GPN labor literature.

\subsection{Dependent Variable: Change in Factory Audit Scores, 2003-2010}

To understand changes in factory conditions, this research used factory-specific audit scores from 2003 and 2010. Unique factory-specific identification numbers the auditors used were employed to link the data across multiple years, and allowed us to examine changes in factory conditions over time. The auditors check to ensure the factory provides adequate security and access to the workers; keeps accurate payroll records; meets age/child labor standards and employee environmental requirements; and has proper worker and government licenses and documentation. Both non-compliance or being denied entrance to the factory automatically results in a failing score. To examine the way factory conditions change over time, we calculated the change in the factory audit scores between 2003 and 2010. Therefore, this change is the 2010 factory audit score minus the 2003 score. The resulting values included positive, negative, and zero values, and were highly skewed. To address the negative and zero values, 3 was added to each case. This increased the value of each change in factory audit score to at least 1 and allowed a log transformation to be applied to maintain a normal distribution. Therefore, the dependent variable in the spatial regression analysis was the change in the log of the factory audit score after the addition of the constant value of 3 .

\subsection{Factory Characteristics}

Previous research on factory compliance and conditions has suggested that factors such as foreign ownership, the type of product manufactured, and the number of employees affect audit scores (Locke 2013). It is important to consider the nationality of the factory owner because foreign owners in many Asian countries are more likely to treat their workers poorly (Moran 2002). The foreign owner variable was coded 1 if the owner is a citizen of a country other than the host country, and 0 otherwise. The type of factory was also controlled in the regression models. There are three main groups in this variable: clothing apparel, light manufacturing - such as toys and electronics—and other types of factories, which include paper and chemical manufacturing. This variable accounted for the differences in the working conditions in factories that produce different types of goods. The total number of workers in 2003 was also controlled in the regression analyses.

\subsection{Neighborhood Effects Variables}

In addition to understanding whether factory auditing improves work conditions, this research argued that neighborhood effects influence changes in factory conditions. The first neighborhood effects variable was whether the factory is located outside the metro core (Jakarta-Indonesia, Manila and Cebu-Philippines, Bangkok-Thailand, Hanoi and Ho Chi Minh-Vietnam). Differences in community norms, managerial styles, perceived value of the environment, and even regional linguistic differences all contribute to major cultural differences between metro core areas and surrounding areas (Tilt 2013; $\mathrm{Li}$ and Tang 2002). It was expected that factories in non-core areas would have smaller changes in audit scores between 2003 and 2010.

To account for the presence of spatial autocorrelation, Moran's I test was performed to test for the presence of spatial autocorrelation in the change in factory audit scores during the period. To do so, all the factories were mapped using the address in the audit report and ArcGIS 10.3 software. The construction and selection of spatial weights is the next important part of a Moran's I test. Currently, 
there is little theoretical guidance on the selection of neighborhoods, or the spatially weighted matrix used in the test (Chi and Zhu 2007). As a result, a comparison of several spatial weight matrices is often performed to examine the way changing the definition of neighborhoods affects the data (Anselin and Getis 2010; Anselin 2002). This research created multiple Moran's I tests using neighborhoods based on threshold distances of $1,5,10$, and $15 \mathrm{~km}$, as well as the k-nearest neighbor that included the 5,10 , and 15 nearest observations. In the end, the k-nearest neighbor test that included the five closest factories was the most effective and thus was used in the final Moran's I test. The results of the test were significant and positive, indicating that the data included spatial autocorrelation. Thus, factories located near one another had similar changes in their audit scores between 2003 and 2010. The positive value indicated that factories near one another experienced similar increases in audit scores. To address the presence of spatial autocorrelation, a spatially lagged variable built with the k-nearest neighbor test that included the five closest factories in the spatially weighted matrix was added to model 2. In addition to accounting for spatial autocorrelation, the spatially lagged variable can provide insights about the way neighborhood effects influence factory audit scores. In short, the lagged variable showed whether the change in conditions neighboring factories reported influence a factory's improvement in audit scores. Finally, a country-level control variable was added to help account for differences between the four countries in the study, with Thailand as the reference country.

\section{Results of Change in Audit Score Analysis}

Table 1 reports the descriptive statistics for the factory audits. In 2003, the average audit score ranged from 63.2 to 69.5 . Thus, the average factory audited had some minor to moderate code of conduct violations. Over the seven years of audits, the factories overall reported a slight increase in their mean audit scores. Vietnam experienced the largest increase, a 5.8 increase between 2003 and 2010. The Philippines (5.1), Indonesia (4.8), and Thailand (4.4) also reported increases in their mean audit scores during that period. These changes in audit scores overall are not very large, and essentially indicate the discontinuation of a minor infraction per factory. These minor improvements in audit scores provide some initial evidence that audits and auditing only have a small effect on factories, even though all the factories received on average over five audits between 2003 and 2010. Finally, Table 1 shows that there was a slight variance in the average number of employees, percentage foreign owned, and percentage located outside a metro core area. However, the factory characteristics across all four countries were relatively similar overall.

Table 1. Descriptive Statistics of Factory Audits.

\begin{tabular}{ccccc}
\hline & Indonesia & Philippines & Thailand & Vietnam \\
\hline Average Audit Score, 2003 & 68.9 & 66.3 & 69.5 & 63.2 \\
Average Audit Score, 2010 & 73.7 & 71.4 & 74.9 & 69.1 \\
Change in Mean Audit Score & 4.8 & 5.1 & 4.4 & 5.8 \\
Average Number of Visits, 2003-2010 & 4.9 & 5.8 & 5.6 & 5.2 \\
Average Number of Employees, 2003 & 612.4 & 681.5 & 722.9 & 534.7 \\
\% Foreign Owned, 2003 & 48.7 & 50.6 & 51.8 & 52.4 \\
\% Outside Metro Core, 2003 & 24.7 & 22.1 & 32.4 & 28.5 \\
N & 180 & 154 & 234 & 264 \\
\hline
\end{tabular}

Next, regression models were estimated to explore the effects of voluntary audits and neighborhood effects on changes in factory conditions. The results are reported in Table 2. Model 1 was a baseline regression of the change in the log of the factory audit scores during the study period. The results indicated that, when other factors were not controlled, the number of visits a factory received between 2003 and 2010 significantly increased the change in auditing scores for that same period. Thus, for every additional visit, a factory reported a small, but significant, improvement in the factory's score overall between 2003 and 2010. Results like this, and the absolute change in 
auditing scores reported in Table 1, provide evidence that audits are effective in improving conditions in GPNs. However, these descriptive and simple statistical approaches fail to account for additional factors associated with factory work conditions and cannot provide a complete understanding of the effectiveness of factory audits. Model 2 presents a more complete assessment of the factors associated with a change in factory audit scores by adding additional factory characteristics and variables associated with differences in neighborhood effects to Model 1.

Table 2. Spatially Lagged Regression Results of the Change in Log Audit Score.

\begin{tabular}{|c|c|c|}
\hline & Model 1 & Model 2 \\
\hline \multicolumn{3}{|l|}{ Factory Characteristics } \\
\hline Number of Visits, 2003-2010 & $1.01^{* *}$ & 0.57 \\
\hline Foreign Owned & & -0.63 \\
\hline Number of Employees & & -0.03 \\
\hline \multicolumn{3}{|l|}{ Apparel (ref) } \\
\hline Manufacturing & & -0.66 \\
\hline Other & & -0.10 \\
\hline \multicolumn{3}{|l|}{ Neighborhood Effects Variables } \\
\hline Outside Metro Core & & $-0.51 *$ \\
\hline Spatial Lag Change in Score & & $0.80^{* * *}$ \\
\hline \multicolumn{3}{|l|}{ Thailand (ref) } \\
\hline Indonesia & & 0.38 \\
\hline Philippines & & -0.27 \\
\hline Vietnam & & $0.39 * *$ \\
\hline Constant & $2.12 * *$ & $1.48^{* *}$ \\
\hline $\mathrm{R}^{2}$ & 0.13 & 0.41 \\
\hline $\mathrm{N}$ & 832 & 832 \\
\hline
\end{tabular}

After more factory characteristics and the neighborhood effects variables were included in Model 2, the variable of the number of audits between 2003 and 2010 was no longer significant. This indicated that the relation between auditing and improved factory conditions was spurious. Further, other factory characteristics, such as whether the factory is foreign owned, the number of employees, and the type of factory, were not significant factors associated with improved conditions. However, many of the neighborhood effect variables significantly influenced the changes in auditing scores between 2003 and 2010. The significance of being outside the metro core suggested that, in addition to corporate and national influences, micro-level neighborhood factors also affect audit scores. Neighborhood effects are present and apparent not only in large cities or metropolitan areas; neighborhood effects can arguably exist in any community, regardless of size, location, or population. Factories outside the main metro core areas reported lower changes in audit scores. This can be the case for a number of reasons. It has been documented well that urban and rural areas vary significantly in a variety of ways, including: cultural norms; employment expectations; and perceived values of environmental and civil factors (Tilt 2013; Li and Tang 2002).

The significant and positive results of the spatially lagged change in scores provided additional support that the neighborhood in which a factory is embedded significantly affects changes in factory conditions over time. This finding can be interpreted as a neighborhood effect and provides additional support that the local neighborhood community in which a factory is embedded has a significant effect on whether or not factory conditions improve. Additionally, our finding is consistent with previous research that found a significant association between neighborhood effects and workers' health (Berkman et al. 2014). Although our data cannot fully explain the causal mechanism between the neighborhood effects and changes in factory conditions, the significance of the spatially lagged variable is still meaningful because it shows that there are important factors that contribute to changes in factory conditions that are currently not being captured by factory audits alone. 
The final variable added to Model 2 was a control variable that accounted for the country in which the factory is located. When compared to the reference country, Thailand, only Vietnam was positive and significant. This finding is consistent with macro labor trends between 2003 and 2010. During that period, Vietnam experienced rapid expansion in foreign investments, and strengthened the protection of workers through new labor laws (Miller et al. 2015; Sanders 2014; Sanders and Brown 2014). This improvement in the macro-level business culture helps account for the fact that factories in Vietnam showed significantly greater increases in factory scores when compared with Thailand.

\section{Dropping “Sweatshops" from the GPN}

While the results of the analysis on the change in factory audit scores showed that the number of audits does not significantly improve factory working conditions, this does not mean that audits cannot improve the quality of a GPN overall. Audits do provide MNCs with insight about the quality of factories in the GPN. Further, as mentioned above, according to deterrence theory and the traditional model of code of conduct compliance, audits can lead to one of two possibilities: (1) improved working conditions, or (2) the MNC dropping the factory in question. Therefore, audits still can help MCNs filter undesirable factories out of their GPNs. To illustrate this point, data from all the factories audited in 2003 were used, and factories were coded 0 if they continued to be audited between 2004 and 2010, and 1 if they were dropped between 2004 and 2010. Next, a logistic regression predicted the likelihood that a factory would be dropped (See Table 3). The results showed that a factory was less likely to be dropped if it reported a higher initial audit score in 2003. Thus, low scoring factories with a higher number of violations were more likely to be dropped from a company's GPN. In addition to the initial audit score, factories with more employees and foreign owned factories were more likely to be dropped.

A final interesting insight provided by determining whether a factory was dropped from a GPN after an initial audit in 2003 is that over 460 factories were dropped between 2003 and 2010. While our data cannot directly determine whether these factories were dropped because of poor labor standards, the large number of factories dropped from the GPNs suggests that MNCs do use audits as a filter. This finding is consistent with deterrence theory and showed that MNCs can use audits to remove factories that perform poorly from their GPNs. Further, this finding provided evidence that auditing is used more appropriately as a way to identify and remove the factories in a GPN that perform worst rather than as a method to improve factory conditions.

Table 3. Logistic Regression Results of the Likelihood that a Factory Will Be Dropped.

\begin{tabular}{cc}
\hline & Odds Ratio \\
\hline Audit Score, 2003 & $0.88^{* * *}$ \\
Number of Employees & $1.03^{* *}$ \\
Apparel (ref) & \\
Manufacturing & 1.25 \\
Other & 1.33 \\
Foreign Owned & $1.82^{* *}$ \\
Outside Metro Core & 1.05 \\
Thailand (ref) & 1.12 \\
Indonesia & 0.98 \\
Philippines & 1.15 \\
Vietnam & -832.67 \\
Log Likelihood & 1293 \\
N &
\end{tabular}




\section{Discussion/Conclusions}

The results of this study showed that, after other factors were controlled, auditing does not improve factory conditions significantly over time. Although previous research that has examined the short-term effects of audits has shown limited improvements associated with factory audits (Egels-Zandén and Lindholm 2015; Locke 2013), this research found no long-term, statistically significant relation between repeated audits and improved factory conditions. Because this is the first study to track changes in specific factories using panel data, our findings provide important new evidence that questions the use of GPN auditing as a way to improve factory conditions.

One limitation of this unique dataset is that it only accounts for factories that STR was contracted to audit and not for other potential factories in a given location. Case studies that address the long-term labor conditions of all factories in a specific area are needed to understand fully the relation between neighborhood conditions and factory labor standards. However, acquiring consistent access to private factories over an extended period of time is extremely difficult. Most MNCs are reluctant to share data or permit researchers access to their GPNs. As a result, the data used in this study, although limited, still provided a unique and important insight into the way audits and labor conditions in GPNs change over time.

The significance of the spatial lag variable in the spatially lagged regression suggested that factory location and neighborhood effects influence working conditions. One possible interpretation of this finding is that if neighboring factories improve their conditions, the remaining factories must follow suit to remain competitive in the local labor market. However, changes in factory conditions associated with the spatial lag variable are more likely associated with changes in neighborhood norms rather than the results of MNCs' externally imposed policies. Previous research that has examined international organizational behavior supports this interpretation of the spatial lag variable results. Multiple papers that have investigated MNC polices implemented internationally contend that local cultural norms have a stronger effect on business environments than policies imposed externally (Hofstede 1993; House et al. 2004). Additional longitudinal research that examines changes in neighborhoods is needed to understand fully the causal mechanism/s between neighborhood effects and changes in factory conditions. Further, this finding suggests that, in addition to auditing reports, simple mapping and cluster analyses available through GIS software can help identify clusters of low performing factories. The added insights that a spatial analysis provides may help improve the effect of auditing on factory conditions overall over time.

Finally, although our results found no statistically significant association between auditing and improvement in factory conditions, the results of the logistic regression analysis suggested that auditing still can be an effective tool to identify and eliminate factories that perform poorly. Therefore, perhaps auditing is not a failed business practice implemented only to protect a company's brand value. Rather than a tool for improvement, the results of this research suggested that auditing should be viewed more appropriately as a filtering mechanism. At a minimum, the expectations and promises of auditing need to be updated to reflect the complex neighborhoods in which CSR codes of conduct are being applied. Failure to do so will only provide more evidence that CSR codes of conduct and auditing are used primarily to protect brand value rather than workers' rights.

Author Contributions: S.R.S. performed the statistical analysis, framed the initial manuscript, and drafted the majority of the paper. M.R.C. developed and wrote the theoretical section addressing neighborhoods, and E.R.P. helped edit and synthesize the theoretical approach used in the paper.

Funding: This research received no external funding.

Acknowledgments: We thank the editors of Social Sciences and the three anonymous reviewers of our work. All of the reviewers provided us with thoughtful and thorough evaluations of our paper. We believe that the revisions we have made based on these comments have allowed us to develop a much-improved manuscript.

Conflicts of Interest: The authors declare no conflicts of interest. 


\section{References}

Anselin, Luc. 2002. Under the hood: Issues in the specification and interpretation of spatial regression models. Agricultural Economics 27: 247-67. [CrossRef]

Anselin, Luc, and Arthur Getis. 2010. Spatial statistical analysis and geographic information systems. In Perspectives on Spatial Data Analysis. Berlin/Heidelberg: Springer, pp. 35-47.

Bartley, Tim. 2005. Corporate accountability and the privatization of labor standards: Struggles over codes of conduct in the apparel industry. Research in Political Sociology 14: 211-44.

Bartley, Tim. 2007. Institutional emergence in an era of globalization: The rise of transnational private regulation of labor and environmental conditions. American Journal of Sociology 113: 297-351. [CrossRef]

Bartley, Tim, and Curtis Child. 2014. Shaming the corporation: The social production of targets and the anti-sweatshop movement. American Sociological Review 79: 653-79. [CrossRef]

Becker, Gary S. 1974. Crime and punishment: An economic approach. In Essays in the Economics of Crime and Punishment. London: Palgrave Macmillan, pp. 1-54.

Berkman, Lisa F., Ichiro Kawachi, and Töres Theorell. 2014. Working conditions and health. In Social Epidemiology. New York: Open University Press, pp. 153-81.

Chan, Jenny, Ngai Pun, and Mark Selden. 2013. The politics of global production: Apple, Foxconn and China's new working class. New Technology, Work and Employment 28: 100-15. [CrossRef]

Chi, Guangqing, and Jun Zhu. 2007. Spatial regression models for demographic analysis. Population Research and Policy Review 27: 17-42. [CrossRef]

Craven, Paul, and Barry Wellman. 1973. The network city. Sociological Inquiry 43: 57-88. [CrossRef]

Egels-Zandén, Niklas. 2014. Revisiting supplier compliance with MNC codes of conduct: Recoupling policy and practice at Chinese toy suppliers. Journal of Business Ethics 119: 59-75. [CrossRef]

Egels-Zandén, Niklas, and Henrik Lindholm. 2015. Do codes of conduct improve worker rights in supply chains? A study of Fair Wear Foundation. Journal of Cleaner Production 107: 31-40. [CrossRef]

Esbenshade, Jill. 2012. A review of private regulation: Codes and auditing in the apparel industry. Sociology Compass 6: 541-56. [CrossRef]

Gereffi, Gary, John Humphrey, and Timothy Sturgeon. 2005. The governance of global value chains. Review of International Political Economy 12: 78-104. [CrossRef]

Guest, Avery M., and Barrett A. Lee. 1984. How urbanites define their neighborhoods. Population and Environment 7: 32-56. [CrossRef]

Hofstede, Geert. 1993. Cultural constraints in management theories. The Academy of Management Executives 7: 81-94. [CrossRef]

House, Robert J., Paul J. Hanges, Mansour Javidan, Peter W. Dorfman, and Vipin Gupta, eds. 2004. Culture, Leadership, and Organizations: The GLOBE Study of 62 Societies. Thousand Oaks: Sage Publications.

Kolben, Kevin. 2004. Trade, monitoring, and the ILO: Working to improve conditions in Cambodia's garment factories. Yale Human Rights \& Development Law Journal 7: 79.

Li, Qiang, and Zhuang Tang. 2002. The rural-urban workers in cities and the irregular employment in cities. Sociological Research 6: 13-25.

Locke, Richard M. 2013. The Promise and Limits of Private Power: Promoting Labor Standards in a Global Economy. Cambridge: Cambridge University Press.

Locke, Richard M., Fei Qin, and Alberto Brause. 2007. Does auditing improve labor standards? Lessons from Nike. Industrial \& Labor Relations Review 61: 3-31.

Locke, Richard, Matthew Amengual, and Akshay Mangla. 2009. Virtue out of necessity? Compliance, commitment, and the improvement of labor conditions in global supply chains. Politics E Society 37: 319-51.

Miller, Terry, Anthony B. Kim, and K. R. Holmes. 2015. 2015 Index of Economic Freedom. Washington: The Heritage Foundation.

Montgomery, Mark R., and Paul C. Hewett. 2005. Urban poverty and health in developing countries: Household and neighborhood effects. Demography 42: 397-425. [CrossRef] [PubMed] 
Moran, Theodore. 2002. The relationship between trade, foreign direct investment, and development: new evidence, strategy, and tactics under the Doha Development Agenda negotiations. Asian Development Bank's Study on Regional Integration and Trade: Emerging Policy Issues for Selected Developing Member Countries. Available online: https: / www.google.com/url?sa=t\&rct=j\&q=\&esrc=s\&source=web\& cd=1\&ved=0ahUKEwiUiqPumqfbAhUDpJQKHTajBe4QFggxMAA\&url=http\%3A\%2F\%2Fciteseerx.ist. psu.edu\%2Fviewdoc\%2Fdownload\%3Fdoi\%3D10.1.1.201.2790\%26rep\%3Drep1\%26type\%3Dpdf\&usg= AOvVaw1CaMuSr-xsr3T4hr9x-vhK. (accessed on 17 May 2016).

Mumford, Lewis. 1961. The City in History. San Diego: Harcourt Inc.

Ngai, Pun. 2005. Global production, company codes of conduct, and labor conditions in China: A case study of two factories. The China Journal 54: 101-13. [CrossRef]

Nisbet, Robert. A. 1969. The Quest for Community. London: Oxford University Press.

Park, Robert E. 1915. The city: Suggestions for the investigation of behavior in the city environment. The American Journal of Sociology 20: 579-83. [CrossRef]

Pickvance, C. G. 1975. Voluntary Associations and the Persistence of Multiple Ties. Ph.D. dissertation, University of Manchester, Manchester, UK.

Sampson, Robert J. 2003. The neighborhood context of well being, supplement. Perspectives in Biology and Medicine 46: S53-64. [CrossRef] [PubMed]

Sampson, Robert J., and Dawn Jeglum Bartusch. 1998. Legal cynicism and (subcultural?) tolerance of deviance: The neighborhood context of racial differences. Law and Society Review 32: 777-804. [CrossRef]

Sampson, Robert J., Stephen W. Raudenbush, and Felton Earls. 1997. Neighborhoods and violent crime: A multilevel study of collective efficacy. Science 277: 918-24. [CrossRef] [PubMed]

Sampson, Robert J., Jeffrey D. Morenoff, and Thomas Gannon-Rowley. 2002. Assessing neighborhood effects: Social processes and new directions in research. Annual Review of Sociology 28: 443-78. [CrossRef]

Sanders, Scott R. 2014. North versus South: The effects of foreign direct investment and historical legacies on poverty reduction in Post-Đổi Mới Vietnam. Journal of Vietnamese Studies 9: 46-67. [CrossRef]

Sanders, Scott R., and David L. Brown. 2014. Escaping poverty in post-socialist Vietnam: Does place matter? Poverty \& Public Policy 6: 332-53.

Seidman, Gay. 2007. Beyond the Boycott. New York: Russell Sage Foundation.

Tilt, Bryan. 2013. The Struggle for Sustainability in Rural China: Environmental Values and Civil Society. New York: Columbia University Press.

Vogel, David. 2010. The private regulation of global corporate conduct: Achievements and limitations. Business $\mathcal{E}$ Society 49: 68-87.

Waddock, Sandra A., Charles Bodwell, and Samuel B. Graves. 2002. Responsibility: The new business imperative. The Academy of Management Executive 16: 132-48. [CrossRef]

Weber, Max. 1978. Max Weber: Selections in Translation. Cambridge: Cambridge University Press.

Wellman, Barry. 1979. The community question: The intimate networks of East Yorkers. The American Journal of Sociology 84: 1201-31. [CrossRef]

Wirth, Louis. 1938. Urbanism as a way of life. The American Journal of Sociology 44: 1-24. [CrossRef]

Woodsworth, James Shaver. 1911. My Neighbor. Toronto: University of Toronto Press.

(C) 2018 by the authors. Licensee MDPI, Basel, Switzerland. This article is an open access article distributed under the terms and conditions of the Creative Commons Attribution (CC BY) license (http://creativecommons.org/licenses/by/4.0/). 